\title{
The EndoPredict score provides prognostic information on late distant metastases in ER + /HER2 - breast cancer patients
}

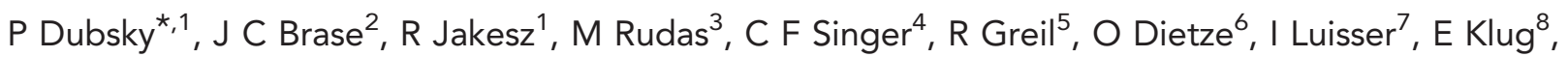
R Sedivy ${ }^{9}, M$ Bachner ${ }^{10}, \mathrm{D}$ Mayr ${ }^{11}, \mathrm{M} \mathrm{Schmidt}^{12}, \mathrm{M} \mathrm{C}$ Gehrmann ${ }^{13}, \mathrm{C} \mathrm{Petry}^{2}, \mathrm{~K} \mathrm{E} \mathrm{Weber}^{2}, \mathrm{~K} \mathrm{Fisch}^{2}$, R Kronenwett ${ }^{2}, M$ Gnant $^{1}$ and M Filipits ${ }^{14}$ on behalf of the Austrian Breast and Colorectal Cancer Study Group (ABCSG)

${ }^{1}$ Department of Surgery and Comprehensive Cancer Center, Medical University Vienna, Vienna, Austria; ${ }^{2}$ Sividon Diagnostics, Cologne, Germany; ${ }^{3}$ Department of Pathology, Medical University Vienna, Vienna, Austria; ${ }^{4}$ Department of Obstetrics and Gynecology, Medical University Vienna, Vienna, Austria; ${ }^{5}$ Medical Department, Paracelsus University of Salzburg, Salzburg, Austria; ${ }^{6}$ Department of Pathology, Paracelsus University of Salzburg, Vienna, Austria; ${ }^{7}$ Department of Surgery, Hospital Guessing, Guessing, Austria; ${ }^{8}$ Department of Pathology, Hospital of Oberwart, Oberwart, Austria; ${ }^{9}$ Department of Pathology, Hospital of St. Poelten, St. Poelten, Austria; ${ }^{10}$ Department of Surgery, Hospital of St. Poelten, St. Poelten, Austria; ${ }^{11}$ Department of Internal Medicine 3, General Hospital of Linz, Linz, Austria; ${ }^{12}$ Department of Gynecology and Obstetrics, University of Mainz, Mainz, Germany; ${ }^{13}$ Bayer Technology Services GmbH, Leverkusen, Germany and ${ }^{14}$ Department of Cancer Research and Comprehensive Cancer Center, Medical University Vienna, Vienna, Austria

Background: ER +/HER2 - breast cancers have a proclivity for late recurrence. A personalised estimate of relapse risk after 5 years of endocrine treatment can improve patient selection for extended hormonal therapy.

Methods: A total of 1702 postmenopausal ER + /HER2 - breast cancer patients from two adjuvant phase III trials (ABCSG6, ABCSG8) treated with 5 years of endocrine therapy participated in this study. The multigene test EndoPredict (EP) and the EPclin score (which combines EP with tumour size and nodal status) were predefined in independent training cohorts. All patients were retrospectively assigned to risk categories based on gene expression and on clinical parameters. The primary end point was distant metastasis (DM). Kaplan-Meier method and Cox regression analysis were used in an early (0-5 years) and late time interval ( $>5$ years post diagnosis).

Results: EP is a significant, independent, prognostic parameter in the early and late time interval. The expression levels of proliferative and ER signalling genes contribute differentially to the underlying biology of early and late DM. The EPclin stratified $64 \%$ of patients at risk after 5 years into a low-risk subgroup with an absolute $1.8 \%$ of late DM at 10 years of follow-up.

Conclusion: The EP test provides additional prognostic information for the identification of early and late DM beyond what can be achieved by combining the commonly used clinical parameters. The EPclin reliably identified a subgroup of patients who have an excellent long-term prognosis after 5 years of endocrine therapy. The side effects of extended therapy should be weighed against this projected outcome.

*Correspondence: Professor P Dubsky; E-mail: peter.dubsky@meduniwien.ac.at

Received 27 June 2013; revised 25 September 2013; accepted 1 October 2013; published online 24 October 2013 
Breast cancer is a heterogeneous disease that may recur soon after initial diagnosis or after a follow-up period of $>10$ years. The recurrence risk varies over time according to molecular and clinical risk factors (Jatoi et al, 2011). ER-negative tumours and HER2 - positive tumours display an increased annual rate of recurrences and deaths after a short period of time (1-3 years). In contrast, ER-positive $(\mathrm{ER}+)$ /HER2-negative (HER2 - ) patients have a considerably lower annual rate in the first years, but the annual recurrence rates persist after the first 5 years (Jatoi et al, 2011).

Despite the initial and sustained benefit of tamoxifen treatment in ER + /HER2 - tumours, $>50 \%$ of all relapses and more than two-thirds of deaths occur more than 5 years after diagnosis (Saphner et al, 1996; EBCTCG, 2005). The persistent risk of ER + / HER2 - breast cancer over time is currently being addressed therapeutically in several large phase III randomised trials of extended endocrine therapy.

The National Cancer Institute of Canada Clinical trials Group (NCIC CTG) MA-17, a randomised, double-blind, placebo-controlled trial, showed that switching from tamoxifen to letrozole after 5 years of tamoxifen treatment improved disease-free survival (Goss et al, 2003; Goss et al, 2005). These results were confirmed by the ABCSG6a trial (Jakesz et al, 2007) using anastrozole for 3 years of extended therapy and the clinical data available from NSABP-33 (Mamounas et al, 2008). More recently, the ATLAS trial reported that 10 years of tamoxifen (in comparison to 5 years) halved mortality rates a decade after diagnosis (Davies et al, 2012). Importantly, close to 20000 patients are currently being treated in phase III clinical trials investigating endocrine treatment beyond 5 years.

Based on published findings, women with ER + disease who have completed 5 years of tamoxifen treatment should be considered for longer duration therapy using aromatase inhibitor (AI) or extended tamoxifen treatment. However, the expected benefit of prolonged anti-hormonal treatment has to be assessed based on toxicity and the individual likelihood of a late recurrence.

A first step to an individualised extended endocrine treatment of late metastases is therefore to identify women at risk and to understand the underlying biology. Clinical factors such as increased tumour size and nodal positivity have been shown to be associated with late relapse (Kennecke et al, 2007). So far, several prognostic multigene tests have been developed for ERpositive breast cancer patients to identify patients with a high risk of relapse (Paik et al, 2004; Parker et al, 2009; Nielsen et al, 2010; Filipits et al, 2011; Dubsky et al, 2012a). However, while these molecular tests are valuable to predict early metastasis, they commonly fail to identify late events (Esserman et al, 2011). This suggests that molecular mechanism may be different for the initiation of early and late relapse.

In summary, individualised estimates of late metastatic risk are a largely unmet medical need with regard to potential benefits of extended anti-hormonal treatment. Here, we assess whether the prognostic EndoPredict (EP) score - a multigene score that combines the expression levels of proliferative and ESR1 signalling/ differentiation-associated genes - identifies late relapse events in $\mathrm{ER}+/ \mathrm{HER} 2-$ breast cancer patients.

\section{MATERIALS AND METHODS}

Patients and samples. Patients included in this study participated in the ABCSG6 (tamoxifen-only arm) or ABCSG8 trial (Schmid et al, 2003; Jakesz et al, 2005; Dubsky et al, 2012b) and received either tamoxifen for 5 years or tamoxifen for 2 years followed by anastrozole for 3 years. None of the patients received adjuvant chemotherapy. Inclusion criteria and clinico-pathological assessment were recently reported by Filipits et al (2011). A total of 378 formalin-fixed, paraffin-embedded (FFPE) samples from ABCSG6 and 1324 FFPE samples from ABCSG8 were combined for the analysis (patient characteristics - Supplementary Table S1). The chosen cohorts represent the validation but not the training sets for the EP test.

Some of the patients from the ABCSG6 and ABCSG8 trials were enrolled into extended endocrine therapy trials (ABCSG6a (Jakesz et al, 2007) and ABCSG16). To avoid any potential bias, all patients with extended therapy were censored at the time of enrolment in ABCSG6a and ABCSG16. So, all patients included in this study were treated with 5 years endocrine therapy only. To ensure that the selective censorship does not lead to any additional selection bias, we compared all molecular and clinical characteristics between patients who were enrolled in extended endocrine trials and those who were not (Supplementary Table S2). Age and treatment arm (tamoxifen $v$ s tamoxifen for 2 years followed by anastrozole for 3 years) were significantly different between the compared subsets. Except for these two variables, there were no significant differences for all other molecular and clinico-pathological parameters.

After censoring patients with extended endocrine therapy, 998 patients were at risk after 5 years with a median follow-up of 7.12 years. Approval for genetic expression analyses and retrospective analyses was obtained from institutional review boards.

EP and EPclin. The EP assay is based on the quantification of eight genes of interest and three normalisation genes in FFPE tissue sections by quantitative RT-PCR (Filipits et al, 2011). The combination of the EP with the two clinical risk factors nodal status and tumour size results in the EPclin. EP and EPclin low-risk and high-risk categories were those pre-specified before the validation in the ABCSG6 and ABCSG8 studies, as recently described (Filipits et al, 2011). Patients with an EP score $<5$ $($ EPclin score $<3.3)$ were classified as low risk for distance recurrence, whereas patients with an EP score $\geqslant 5$ (EPclin score $\geqslant 3.3$ ) were stratified as high risk.

Exploratory analysis - biological signatures/modules associated with late recurrence. The gene expression levels of the EP signature were analysed according to the two time periods $(0-5$ years, early recurrence and $>5$ years, late recurrence). The analysis was carried out using the eight EP genes, and there was no comprehensive review of other predictive markers for late recurrence in high-throughput data sets. Therefore, the analyses should be regarded as hypothesis-generating.

The gene expression data were used to study the most common biological signatures that are combined in the EP test. Relative expression levels of the eight genes of interest were calculated as $d C_{t}$ values with regard to the three reference genes: $d C_{t}=20-C_{t}$ (gene of interest) $+C_{t}$ (mean of reference genes). Two different molecular modules were defined: $d C_{t}$ levels of BIRC5, UBE2C and DHCR7 were used as a surrogate marker for proliferation/ cell cycle. The linear combination of the three $d C_{t}$ values (BIRC5, UBE2C and DHCR7) was calculated using the same coefficients as in the EP risk score for all analysed samples: Proliferation $=0.41 \cdot d C_{t}($ BIRC5 $)+0.39 \cdot d C_{t}($ UBE2C $)+0.39 \cdot d C_{t}($ DHCR7 $)$.

As with the proliferation metagene, the linear combination of the $d C_{t}$ values of RBBP8, IL6ST, AZGP1, MGP and STC2 was used as a surrogate marker for ESR1-related signalling/cell differentiation: ERsignalling $=0.35 \cdot d C_{t}(R B B P 8)+0.31 \cdot d C_{t}($ IL6ST $)+0.26 \cdot d C_{t}(A Z G P 1)+0.18$ $\cdot d C_{t}(M G P)+0.15 \cdot d C_{t}(S T C 2)$.

Statistical analysis. The primary end point of the statistical analysis was distant metastasis. Metastasis rates were estimated using the Kaplan-Meier method. All reported $P$-values are results of two-sided tests. $P$-values $<5 \%$ were considered statistically significant. EP/EPclin was calculated using MATLAB software, version R2011b (The MathWorks, Inc., Natick, MA, USA). P-values and hazard rates were assessed in two different time intervals (0-5 years, $>5$ years) according to the different parameters. 
The c-index was used to assess the prognostic performance of the EP signature and clinico-pathological parameters. Its unbiased estimation for a combination of variables and its use to determine whether a variable adds significant information to a set of other variables was calculated as recently described. Clinico-pathological variables were used for multivariate analysis and c-index analysis as recently described (Filipits et al, 2011).

\section{RESULTS}

The EP score identifies early and late relapse events. To assess the impact of the EP score and clinico-pathological parameters on the prediction of early and late metastases, we retrospectively analysed 1702 ER-positive, HER2 - negative postmenopausal breast cancer patients from the ABCSG6 and 8 trials (patient characteristics - Supplementary Table S1).

In all, $49 \%(n=832)$ of all patients were classified as low risk according to the EP score. Kaplan-Meier analysis demonstrated that the EP low-risk group had a significantly improved clinical outcome in the first $(0-5$ years; $P<0.001)$ and second time interval ( $>5$ years; $P=0.002$; Figure 1 ). The EP low-risk group showed an absolute freedom of distance recurrence of $96.29 \%(93.48 \%-$ 99.11\%) between 5 and 10 years of follow-up. Nodal status was also significantly associated with the clinical outcome in both time intervals, with node-positive tumours showing a considerably higher rate of late recurrence events in comparison to patients with node-negative disease (Supplementary Figure S1). In contrast, grading and Ki67 levels were not significantly associated with late metastases (Supplementary Figure S2). Multivariate analysis showed that EP is an independent prognostic parameter after adjustment for age, grade, lymph node status, tumour size and Ki67 in the first and second time interval (Table 1).

Contribution of proliferative and ER signalling/differentiationassociated genes to early and late relapse events - an explorative analysis. The EP test identified a subgroup of patients who have a low likelihood of developing early and late metastases. Multivariate analyses demonstrated that the test provides complimentary prognostic information to clinico-pathological parameters. To analyse the underlying biology behind these findings, the prognostic genes of the EP test were subdivided according to biological functions. Although, the genes of interest cover several cellular processes such as apoptosis, DNA repair, cell adhesion, and cell signalling, the genes are also co-regulated with genes reflecting two relevant biological modules known to contribute to recurrence risk: proliferation and ER signalling/differentiation. The expression levels of BIRC5, UBE2C and DHCR7 were used as a surrogate marker for proliferation/cell cycle, whereas the expression levels of RBBP8, IL6ST, AZGP1, MGP and STC2 were used as a surrogate marker for ER signalling/cell differentiation.

Multivariate analysis included the same variables described previously (Table 1) but the multigene algorithm is now subdivided into the surrogates of proliferation and ER signalling. Proliferation genes add independent prognostic information to all clinical parameters included into the model for the prediction of early recurrences ( $0-5$ years): a high expression of genes - thought to contribute to cell cycle progression - is significantly associated with higher rates of distant metastasis during the first 5 years but no longer shows a significant additional prognostic performance during the timespan thereafter (Table 2). In contrast, genes associated with ER signalling were not significantly associated with early metastases but showed additional prognostic information in the second time interval (Table 2).

Combination of molecular and clinical parameters improves the prediction of late recurrences. C-indices, a statistical measure of prognostic performance, were calculated for all common clinicopathological parameters and the EP test to assess the prognostic

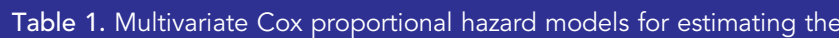
contribution of variables to predict distant recurrence in the time interval $0-5$ years and after 5 years (1702 ER + /HER2 - tumours, ABCSG6/8)

\begin{tabular}{|l|r|r|r|r|}
\hline Variable & $\begin{array}{c}\text { 0-5 years unit } \\
\text { HR (95\% Cl) }\end{array}$ & P-value & $\begin{array}{c}\text { >5 years unit } \\
\text { HR (95\% CI) }\end{array}$ & P-value \\
\hline EP & $1.20(1.10-1.31)$ & $<0.001$ & $1.28(1.10-1.48)$ & 0.001 \\
\hline Age & $1.03(1.00-1.06)$ & 0.032 & $0.97(0.93-1.02)$ & 0.264 \\
\hline Nodal status & $2.15(1.67-2.77)$ & $<0.001$ & $2.45(1.58-3.81)$ & $<0.001$ \\
\hline Tumour size & $1.26(0.94-1.70)$ & 0.121 & $1.11(0.67-1.86)$ & 0.679 \\
\hline Ki67 & $1.01(0.99-1.03)$ & 0.171 & $1.01(0.97-1.05)$ & 0.761 \\
\hline Grade & $1.21(0.77-1.90)$ & 0.414 & $0.64(0.32-1.28)$ & 0.210 \\
\hline $\begin{array}{l}\text { Treatment } \\
\text { arm }\end{array}$ & $0.95(0.61-1.48)$ & 0.807 & $0.91(0.40-2.09)$ & 0.827 \\
\hline
\end{tabular}

Abbreviations: $\mathrm{Cl}=$ confidence interval; $\mathrm{ER}=$ oestrogen receptor; $\mathrm{HR}=$ hazard ratio.

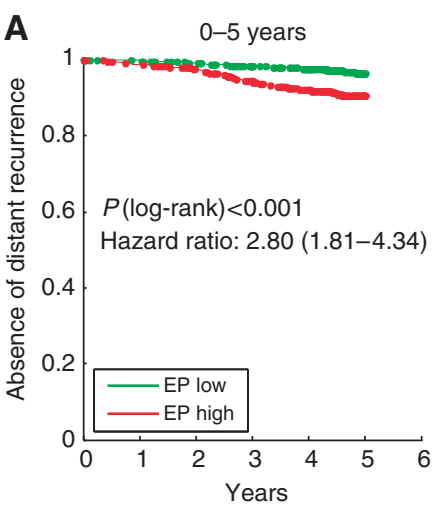

Numbers at risk:

$832821806 \quad 779740 \quad 540$

$870 \quad 853 \quad 826 \quad 778 \quad 725 \quad 515$

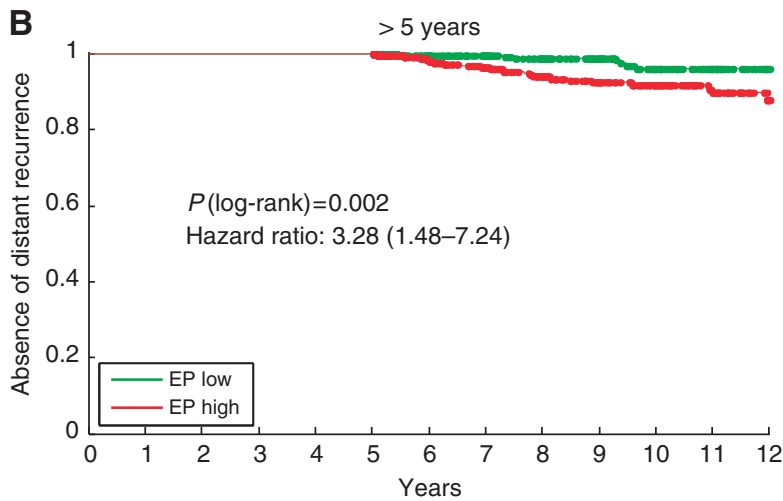

Numbers at risk:

$\begin{array}{llllllll}503 & 322 & 266 & 218 & 173 & 122 & 85 & 43\end{array}$

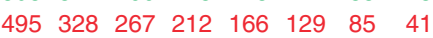

Figure 1. Kaplan-Meier plots. Kaplan-Meier plots of distant recurrence by the EP groups between (A) 0-5 years of follow-up and (B) 5-10 years of follow-up in the combined ER + /HER2 - cohort (ABCSG6/8, $n=1702$ ). Cutoff point for EP was prespecified at 5 . The numbers in parentheses indicate the $95 \% \mathrm{Cl}$ of the $\mathrm{HR}$. 
Table 2. Multivariate Cox proportional hazard models for estimating the contribution of variables to predict distant recurrence in the time interval 0-5 years and after 5 years (1702 ER + /HER2 - tumours, ABCSG6/8)

\begin{tabular}{|l|c|r|c|c|}
\hline Variable & $\begin{array}{c}\mathbf{0}-\mathbf{5} \text { years unit } \\
\text { HR (95\% Cl) }\end{array}$ & $\boldsymbol{P}$-value & $\begin{array}{c}>\mathbf{5} \text { years unit } \\
\text { HR }(\mathbf{9 5 \%} \text { Cl) }\end{array}$ & $\boldsymbol{P}$-value \\
\hline Proliferation & $1.60(1.33-1.92)$ & $<0.001$ & $1.19(0.85-1.67)$ & 0.298 \\
\hline $\begin{array}{l}\text { ER } \\
\text { signalling }\end{array}$ & $0.89(0.75-1.06)$ & 0.204 & $0.61(0.46-0.81)$ & $<0.001$ \\
\hline Age & $1.03(1.00-1.06)$ & 0.040 & $0.98(0.93-1.02)$ & 0.356 \\
\hline $\begin{array}{l}\text { Nodal } \\
\text { status }\end{array}$ & $2.20(1.71-2.83)$ & $<0.001$ & $2.50(1.60-3.90)$ & $<0.001$ \\
\hline Tumour size & $1.26(0.94-1.70)$ & 0.123 & $1.15(0.69-1.93)$ & 0.585 \\
\hline Ki67 & $1.00(0.98-1.03)$ & 0.728 & $1.01(0.97-1.06)$ & 0.502 \\
\hline Grade & $1.23(0.78-1.93)$ & 0.364 & $0.69(0.35-1.36)$ & 0.286 \\
\hline $\begin{array}{l}\text { Treatment } \\
\text { arm }\end{array}$ & $0.92(0.59-1.43)$ & 0.712 & $0.89(0.39-2.05)$ & 0.784 \\
\hline
\end{tabular}

Abbreviations: $\mathrm{Cl}=$ confidence interval; $\mathrm{ER}=$ oestrogen receptor; $\mathrm{HR}=$ hazard ratio Proliferation module was determined by the linear combination of the $d C_{t}$ values of $B I R C 5$, $D H C R 7$, and UBE2C. ER signalling module was determined by the linear combination of the $d C_{t}$ values of AZGP1, IL6ST, MGP, RBBP8, and STC2.

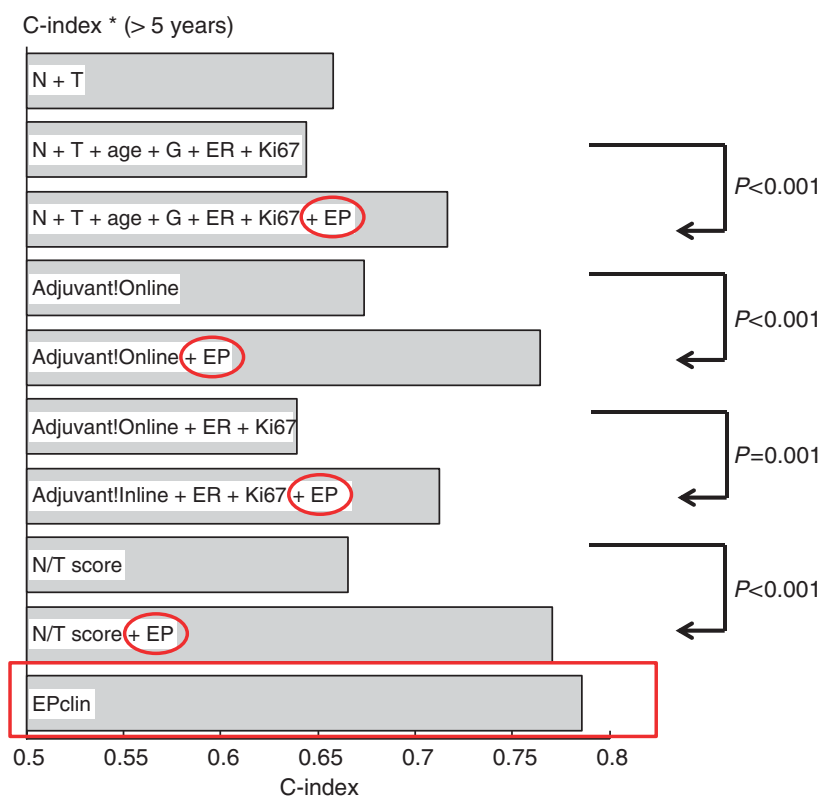

Figure 2. C-indices demonstrating the prognostic performance of different clinical and molecular parameters in $1702 \mathrm{ER}+/$ HER2 - breast cancer patients (ABCSG6/8) after 5 years of follow-up. The values on the $x$ axis are unbiased estimates of the c-index of the linear combination of one or more variables by Cox regression. Statistical tests indicate whether the c-index increases significantly by addition of EP to a fixed set of clinico-pathological variables. Abbreviations: EP, EndoPredict (continuous); ER, oestrogen receptor (categorical); G, grade (categorical); N, nodal status (categorical); $T$, tumour size (categorical).

performance and individual contribution to the prediction of late distant metastasis (Figure 2). The combination of clinical parameters resulted in a c-index of 0.644 in the combined cohort. The addition of the EP score to the combination of clinicopathological parameters resulted in a c-index of 0.716 . The prognostic performance was significantly improved adding the molecular information of the EP test $(P<0.001$; Figure 2).
Comparable results were obtained when the Adjuvant! Online score was used for classification: c-index for prediction of late metastases significantly increased from 0.674 to 0.765 by adding the prognostic information of the EP score. Adjuvant! Online, Ki67 and quantitative ER IHC were further combined resulting in a c-index of 0.64. EP also improved the combination of these parameters (Figure 2, c-index: 0.713). Analysis of proliferation and ESR1 signalling modules demonstrated that ER signalling contributes to the prognostic performance, whereas the addition of the proliferation module did not show a significant effect (Supplementary Figure S3). These results provide further evidence that ESR1 signalling is biologically involved in late metastasis.

The EPclin - a predefined combination of the EP and the clinical risk factors nodal status and tumour size - showed the best performance in predicting late relapse events with a c-index of 0.786 (Figure 2). Splitting the EPclin score into the clinical and molecular information demonstrated that the molecular information (EP score) adds significant $(P<0.001$; Figure 2) prognostic information to the weighted clinical score of nodal status and tumour size $(\mathrm{N} / \mathrm{T} \quad$ score $=0.35 \cdot \mathrm{T}+0.64 \cdot \mathrm{N})$. C-index was increased from 0.666 to 0.771 , which is still smaller compared with the predefined EPclin score (0.786, Figure 2). EPclin subgroups were further analysed using Kaplan-Meier curves with dichotomised EPclin low- and EPclin high-risk groups. Significant differences in metastasis-free survival were found between the EPclin risk groups between 0 and 5 years and after 5 years of follow-up (Figure 3). After 10 years of follow-up absolute freedom of distance recurrence of patients with EPclin low-risk and EPclin high-risk were $98.20 \%(96.54-99.85 \%)$ and $87.69 \%$ (82.86$92.52 \%)$, respectively.

EP as well as EPclin were also significantly associated with early and late recurrences when the analyses were restricted to patients who had been treated with 5 years of tamoxifen (excluding patients treated with tamoxifen for 2 years followed by anastrozole for 3 years; Supplementary Figure S4).

\section{DISCUSSION}

In this study, we have assessed whether clinical and pathological variables and the multigene expression signature EP are associated with distant metastasis arising later than 5 years after the diagnosis of breast cancer.

This is a retrospective analysis of a large biomarker sample set obtained from two phase III clinical trials from ABCSG asking endocrine treatment questions and relying on prospectively acquired clinical data (Schmid et al, 2003; Dubsky et al, 2012b). This sample set has previously been analysed to validate the EP test (none of these samples were included in the training phase) (Filipits et al, 2011). According to the revised level of evidence classification by Simon et al (2009), the EP test has level Ib evidence.

We show that EP is significantly associated with both early and late distant metastasis and that the signature provides additional prognostic information regarding late metastasis to common prognostic variables or a combination thereof (e.g., the Adjuvant! Online algorithm). An exploratory analysis of the biological modules contained in the EP score suggests that the expression of genes thought to be regulated by the oestrogen receptor contribute to late distant metastatic risk. A high expression of these genes is associated with a lower incidence of late distant metastasis in this homogenous cohort of women treated with endocrine treatment in the absence of chemotherapy.

The basic hypothesis of this analysis states that tumour-derived biological factors contribute to late distant metastasis. However, during a full decade of survivorship many other factors may have a profound impact on cancer recurrence: the retrospective nature of our analysis does not account for changes in lifestyle, not for all 
A

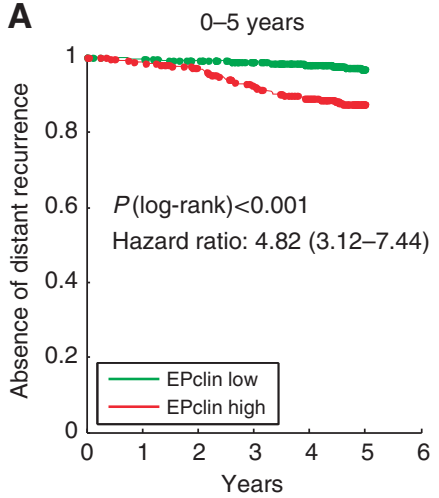

Numbers at risk:

1066105610381006955682 $\begin{array}{llllll}636 & 618 & 594 & 551 & 510 & 373\end{array}$

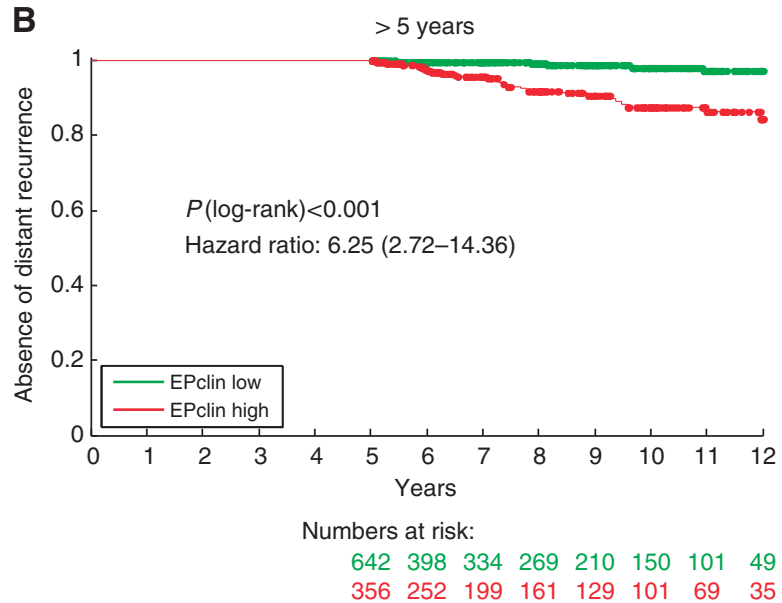

Figure 3. Kaplan-Meier plots. Kaplan-Meier plot of distant recurrence by EPclin groups between (A) 0-5 years of follow-up and (B) 5-10 years of follow-up in the combined ER + /HER2 - cohort (ABCSG6/8, $n=1702$ ). Cutoff point for EPclin was prespecified at 3.3. The numbers in parentheses indicate the $95 \% \mathrm{Cl}$ of the $\mathrm{HR}$.

competing health problems or psychosocial issues. In line with assumptions that would prioritise host factors, the training of firstgeneration multigene signatures was carried out to predict early but not late recurrence. For instance, Mammaprint was developed to identify metastases that occurred within 5 years after initial diagnosis (van 't Veer et al, 2002). Most of the prognostic multigene tests heavily rely on genes associated with cell cycle progression/proliferation. Not surprisingly, these signatures failed to identify late events (Esserman et al, 2011; Sgroi et al, 2013). For instance, the Oncotype DX assay failed to identify late distant metastases in the ATAC trial (Sgroi et al, 2013). In contrast, the Breast Cancer Index (BCI) was found to be a significant prognostic factor in the same trial (Sgroi et al, 2013). BCI combines genes that are associated with proliferation and oestrogen-receptor signalling (Ma et al, 2008). Our analysis also suggested that proliferation genes predict early recurrence events but show a decreased prognostic performance after 5 years of follow-up. The results indicate that underlying molecular mechanism leading to the development of early - as opposed to late - metastases differ substantially.

Additionally, we analysed how clinical factors contribute to the prediction of late relapse events. As already described by Kennecke et al (2007), nodal status and tumour size are important prognostic parameters for late recurrences. So both, molecular and clinical parameters contribute to the underlying biology of late distant metastases. The EPclin, a previously validated score that in addition to gene expression incorporates tumour size and nodal status, was consequently identified to be the best predictor of late recurrence events and correctly identifies a large subset of patients with very low late relapse rates.

The main limitation of this study lies within the biomarker sample gained from ABCSG6 and ABCSG8. Both studies addressed endocrine treatment questions in the absence of adjuvant or neoadjuvant chemotherapy. Accordingly, there is a clear selection bias toward clinically low-risk ER + postmenopausal breast cancer patients: only one-third of patients had involved lymph nodes and only $5 \%>3$ metastatic nodes. In all, $32 \%$ had T2 tumours and only $2 \%$ were $>5 \mathrm{~cm}$. Due to the inclusion criteria and the study designs, only $4 \%$ of women had high-grade differentiation. A total of 998 women were at risk 5 years after diagnosis and the median follow-up of this group is just over 7 years. Clearly, an even longer follow-up for a study that specifically investigates late relapse would be desirable but could not be obtained for the current analysis. This is partially due to the fact that some of the patients from the ABCSG6 and ABCSG8 trials were censored for the late time interval, because they were treated with extended adjuvant therapy (ABCSG6a, ABCSG16). We decided to censor those patients to analyse a homogenous cohort of ER +/HER2 - breast cancer patients who were treated with 5 years of endocrine therapy only. We tested whether the selective censorship could potentially lead to any bias. Age and treatment arm (tamoxifen $v s$ tamoxifen/ anastrozole) were significantly different between patients who were enrolled into ABCSG6a/ABCSG16 and those patients who were not. This is due to the fact that younger patients were more frequently recruited for extented endocrine trials. As age is not a prognostic parameter in postmenopausal breast cancer patients, it is unlikely that the results could have been overestimated or underestimated. None of the other molecular and clinical parameters was significantly different between the compared groups.

The 5 years cutoff was chosen, because most patients are commonly treated with 5 years of endocrine therapy, and the decision whether to prolong adjuvant endocrine treatment is normally made after 5 years of treatment. Other cutoff levels might also be reasonable for future studies in case that prolonged followup data is available.

With regard to these limitations, our findings are in need of validation in further populations; retrospective analysis of phase III trials investigating extended endocrine treatment would be preferable.

ER + /HER2 - breast cancer displays a proclivity for late recurrence. Several phase III trials have addressed this issue and are addressing this medical need therapeutically by testing extended adjuvant therapy. Prospective and retrospective analyses from these data sets suggest that women with premenopausal status at diagnosis (Goss et al, 2013), with a co-expression of ER and PgR (Jakesz et al, 2007), a larger tumour size (Mamounas et al, 2008) and involved lymph nodes (Goss et al, 2005) derive an increased benefit from extended AI treatment. Data showing significant statistical interaction with extended adjuvant treatment that would suggest a predictive factor are lacking.

In the absence of predictive factors, the identification of women with an extremely low risk who can be spared a full decade of endocrine treatment is an important goal of clinical research. The low-risk group of women identified by the EPclin score comprises $64 \%$ of patients from our biomarker sample after 5 years of follow-up. These patients have an absolute risk of distant metastasis of $1.8 \%$ between 5 and 10 years of follow-up and might be sufficiently treated with 5 years of adjuvant endocrine therapy. The side effects and the economic burden of extended adjuvant endocrine therapy in addition to competing health risks should be weighed against such a projected outcome. 


\section{CONFLICT OF INTEREST}

$\mathrm{PD}, \mathrm{MF}$ and MS have received honoraria from Sividon Diagnostics $\mathrm{GmbH}$ for lectures concerning EP. RG has had an advisory role, received travel and research support from Astra Zeneca. JCB, KF, $\mathrm{CP}, \mathrm{KEW}$ and RK are employees of Sividon Diagnostics GmbH. $\mathrm{CP}, \mathrm{KEW}$ and RK are shareholders of Sividon Diagnostics GmbH. The other authors declare no conflicts of interest.

\section{REFERENCES}

Davies C, Pan H, Godwin J, Gray R, Arriagada R, Raina V, Abraham M, Alencar VH, Badran A, Bonfill X, Bradbury J, Clarke M, Collins R, Davis SR, Delmestri A, Forbes JF, Haddad P, Hou MF, Inbar M, Khaled H, Kielanowska J, Kwan WH, Mathew BS, Mittra I, Muller B, Nicolucci A, Peralta O, Pernas F, Petruzelka L, Pienkowski T, Radhika R, Rajan B, Rubach MT, Tort S, Urrutia G, Valentini M, Wang Y, Peto R (2012) Long-term effects of continuing adjuvant tamoxifen to 10 years versus stopping at 5 years after diagnosis of oestrogen receptor-positive breast cancer: ATLAS, a randomised trial. Lancet 381: 805-816.

Dubsky P, Filipits M, Jakesz R, Rudas M, Singer C, Greil R, Dietze O, Luisser I, Klug E, Sedivy R, Bachner M, Mayr D, Schmidt M, Gehrmann M, Petry C, Weber K, Kronenwett R, Brase J, Gnant M. (ABCSG). (2012a) EndoPredict improves the prognostic classification derived from common clinical guidelines in ER-positive, HER2 - negative early breast cancer. Ann Oncol 24: 640-647.

Dubsky PC, Jakesz R, Mlineritsch B, Postlberger S, Samonigg H, Kwasny W, Tausch C, Stoger H, Haider K, Fitzal F, Singer CF, Stierer M, Sevelda P, Luschin-Ebengreuth G, Taucher S, Rudas M, Bartsch R, Steger GG, Greil R, Filipcic L, Gnant M (2012b) Tamoxifen and anastrozole as a sequencing strategy: a randomized controlled trial in postmenopausal patients with endocrine-responsive early breast cancer from the Austrian Breast and Colorectal Cancer Study Group. J Clin Oncol 30: 722-728.

EBCTCG (2005) Effects of chemotherapy and hormonal therapy for early breast cancer on recurrence and 15-year survival: an overview of the randomised trials. Lancet 365(9472): 1687-1717.

Esserman LJ, Moore DH, Tsing PJ, Chu PW, Yau C, Ozanne E, Chung RE, Tandon VJ, Park JW, Baehner FL, Kreps S, Tutt AN, Gillett CE, Benz CC (2011) Biologic markers determine both the risk and the timing of recurrence in breast cancer. Breast Cancer Res Treat 129(2): 607-616.

Filipits M, Rudas M, Jakesz R, Dubsky P, Fitzal F, Singer CF, Dietze O, Greil R, Jelen A, Sevelda P, Freibauer C, Muller V, Janicke F, Schmidt M, Kolbl H, Rody A, Kaufmann M, Schroth W, Brauch H, Schwab M, Fritz P, Weber KE, Feder IS, Hennig G, Kronenwett R, Gehrmann M, Gnant M (2011) A new molecular predictor of distant recurrence in ER-positive, HER2 - negative breast cancer adds independent information to conventional clinical risk factors. Clin Cancer Res 17(18): 6012-6020.

Goss PE, Ingle JN, Martino S, Robert NJ, Muss HB, Livingston RB, Davidson NE, Perez EA, Chavarri-Guerra Y, Cameron DA, Pritchard KI, Whelan T, Shepherd LE, Tu D (2013) Impact of premenopausal status at breast cancer diagnosis in women entered on the placebo-controlled NCIC CTG MA17 trial of extended adjuvant letrozole. Ann Oncol 24(2): 355-361.

Goss PE, Ingle JN, Martino S, Robert NJ, Muss HB, Piccart MJ, Castiglione M, Tu D, Shepherd LE, Pritchard KI, Livingston RB, Davidson NE, Norton L, Perez EA, Abrams JS, Cameron DA, Palmer MJ, Pater JL (2005) Randomized trial of letrozole following tamoxifen as extended adjuvant therapy in receptor-positive breast cancer: updated findings from NCIC CTG MA.17. J Natl Cancer Inst 97(17): 1262-1271.

Goss PE, Ingle JN, Martino S, Robert NJ, Muss HB, Piccart MJ, Castiglione M, Tu D, Shepherd LE, Pritchard KI, Livingston RB, Davidson NE, Norton L, Perez EA, Abrams JS, Therasse P, Palmer MJ, Pater JL (2003) A randomized trial of letrozole in postmenopausal women after five years of tamoxifen therapy for early-stage breast cancer. N Engl J Med 349(19): 1793-1802.

Jakesz R, Greil R, Gnant M, Schmid M, Kwasny W, Kubista E, Mlineritsch B, Tausch C, Stierer M, Hofbauer F, Renner K, Dadak C, Rucklinger E, Samonigg H (2007) Extended adjuvant therapy with anastrozole among postmenopausal breast cancer patients: results from the randomized Austrian Breast and Colorectal Cancer Study Group Trial 6a. J Natl Cancer Inst 99(24): 1845-1853.

Jakesz R, Jonat W, Gnant M, Mittlboeck M, Greil R, Tausch C, Hilfrich J, Kwasny W, Menzel C, Samonigg H, Seifert M, Gademann G, Kaufmann M, Wolfgang J (2005) Switching of postmenopausal women with endocrine-responsive early breast cancer to anastrozole after 2 years adjuvant tamoxifen: combined results of ABCSG trial 8 and ARNO 95 trial. Lancet 366(9484): 455-462.

Jatoi I, Anderson WF, Jeong JH, Redmond CK (2011) Breast cancer adjuvant therapy: time to consider its time-dependent effects. J Clin Oncol 29(17): 2301-2304.

Kennecke HF, Olivotto IA, Speers C, Norris B, Chia SK, Bryce C, Gelmon KA (2007) Late risk of relapse and mortality among postmenopausal women with estrogen responsive early breast cancer after 5 years of tamoxifen. Ann Oncol 18(1): 45-51.

Ma XJ, Salunga R, Dahiya S, Wang W, Carney E, Durbecq V, Harris A, Goss P, Sotiriou C, Erlander M, Sgroi D (2008) A five-gene molecular grade index and HOXB13:IL17BR are complementary prognostic factors in early stage breast cancer. Clin Cancer Res 14(9): 2601-2608.

Mamounas EP, Jeong JH, Wickerham DL, Smith RE, Ganz PA, Land SR, Eisen A, Fehrenbacher L, Farrar WB, Atkins JN, Pajon ER, Vogel VG, Kroener JF, Hutchins LF, Robidoux A, Hoehn JL, Ingle JN, Geyer Jr CE, Costantino JP, Wolmark N (2008) Benefit from exemestane as extended adjuvant therapy after 5 years of adjuvant tamoxifen: intention-to-treat analysis of the National Surgical Adjuvant Breast And Bowel Project B-33 trial. J Clin Oncol 26(12): 1965-1971.

Nielsen TO, Parker JS, Leung S, Voduc D, Ebbert M, Vickery T, Davies SR, Snider J, Stijleman IJ, Reed J, Cheang MC, Mardis ER, Perou CM, Bernard PS, Ellis MJ (2010) A comparison of PAM50 intrinsic subtyping with immunohistochemistry and clinical prognostic factors in tamoxifentreated estrogen receptor-positive breast cancer. Clin Cancer Res 16(21): 5222-5232.

Paik S, Shak S, Tang G, Kim C, Baker J, Cronin M, Baehner FL, Walker MG, Watson D, Park T, Hiller W, Fisher ER, Wickerham DL, Bryant J, Wolmark N (2004) A multigene assay to predict recurrence of tamoxifentreated, node-negative breast cancer. N Engl J Med 351(27): 2817-2826.

Parker JS, Mullins M, Cheang MC, Leung S, Voduc D, Vickery T, Davies S, Fauron C, He X, Hu Z, Quackenbush JF, Stijleman IJ, Palazzo J, Marron JS, Nobel AB, Mardis E, Nielsen TO, Ellis MJ, Perou CM, Bernard PS (2009) Supervised risk predictor of breast cancer based on intrinsic subtypes. J Clin Oncol 27(8): 1160-1167.

Saphner T, Tormey DC, Gray R (1996) Annual hazard rates of recurrence for breast cancer after primary therapy. J Clin Oncol 14(10): 2738-2746.

Schmid M, Jakesz R, Samonigg H, Kubista E, Gnant M, Menzel C, Seifert M, Haider K, Taucher S, Mlineritsch B, Steindorfer P, Kwasny W, Stierer M, Tausch C, Fridrik M, Wette V, Steger G, Hausmaninger H (2003) Randomized trial of tamoxifen versus tamoxifen plus aminoglutethimide as adjuvant treatment in postmenopausal breast cancer patients with hormone receptor-positive disease: Austrian breast and colorectal cancer study group trial 6. J Clin Oncol 21(6): 984-990.

Sgroi DC, Sestak I, Cuzick J, Zhang Y, Schnabel CA, Schroeder B, Erlander MG, Dunbier A, Sidhu K, Lopez-Knowles E, Goss PE, Dowsett M (2013) Prediction of late distant recurrence in patients with oestrogenreceptor-positive breast cancer: a prospective comparison of the breast-cancer index (BCI) assay, 21-gene recurrence score, and IHC4 in the TransATAC study population. Lancet Oncol 14(11): 1067-1076.

Simon RM, Paik S, Hayes DF (2009) Use of archived specimens in evaluation of prognostic and predictive biomarkers. J Natl Cancer Inst 101(21): 1446-1452.

van 't Veer LJ, Dai H, van de Vijver MJ, He YD, Hart AA, Mao M, Peterse HL, van der Kooy K, Marton MJ, Witteveen AT, Schreiber GJ, Kerkhoven RM, Roberts C, Linsley PS, Bernards R, Friend SH (2002) Gene expression profiling predicts clinical outcome of breast cancer. Nature 415(6871): 530-536.

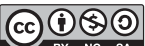

This work is licensed under a Creative Commons Attribution-NonCommercial-ShareAlike 3.0 Unported License. To view a copy of this license, visit http://creativecommons.org/licenses/by-nc-sa/3.0/

Supplementary Information accompanies this paper on British Journal of Cancer website (http://www.nature.com/bjc) 